\title{
Effectiveness of Intra-Articular Ropivacaine for Post-Operative Analgesia in Arthroscopic Knee Surgeries
}

\author{
Pratibha Nagpure ${ }^{1}$, Anjali Modak ${ }^{2}$, Amol Singam ${ }^{3}$, Shruti Shrey4 ${ }^{4}$ Basant Latwal ${ }^{5}$, Ayushma Jejani ${ }^{6}$
}

${ }^{1}$ Department of Anaesthesiology, AVBRH, JNMC, Sawangi, Wardha, Maharashtra, India. ${ }^{2}$ Department of Anaesthesiology, AVBRH, JNMC, Sawangi, Wardha, Maharashtra, India. ${ }^{3}$ Department of Anaesthesiology, AVBRH, JNMC, Sawangi, Wardha, Maharashtra, India. ${ }^{4}$ Department of Anaesthesiology, AVBRH, JNMC, Sawangi, Wardha,

Maharashtra, India. ${ }^{5}$ Department of Anaesthesiology, AVBRH, JNMC, Sawangi, Wardha, Maharashtra, India. ${ }^{6}$ Department of Anaesthesiology, AVBRH, JNMC, Sawangi, Wardha, Maharashtra, India.

\section{ABSTRACT}

\section{BACKGROUND}

Post-operative pain frequently hampers implementation of day care arthroscopic knee surgery in spite of so many analgesic, local anaesthetic drugs and routes of administration. The aim of this study was to evaluate the efficacy and safety of intraarticularly administered inj. ropivacaine $0.25 \% 20 \mathrm{ml}$, after arthroscopic knee surgery performed under spinal anaesthesia, for prolonging the duration of postoperative analgesia.

\section{METHODS}

This is a prospective randomized study conducted among 80 patients of both sexes, of American Society of Anesthesiologists, physical status I and II, undergoing day care arthroscopic knee surgery who were randomly assigned into two groups $(R, C)$. Group $\mathrm{R}$ received $20 \mathrm{ml}$ of $0.25 \%$ ropivacaine, whereas group $\mathrm{C}$ received $20 \mathrm{ml}$ of $0.9 \%$ inj. normal saline through intra-articular route at the end of the procedure. Pain was assessed using visual analog scale (VAS) and paracetamol given as rescue analgesic when VAS $>4$. Time of first analgesic request and total rescue analgesic were noted.

\section{RESULTS}

Time for the requirement of first post-operative rescue analgesia $(255.15 \pm 26.35$ vs. $92.40 \pm 12.54) \mathrm{min}$ and total mean rescue analgesic requirement was $(1.32 \pm 0.52$ vs. $3.0 \pm 1.0$ ) in group $\mathrm{R}$ and $\mathrm{C}$ respectively. Group $\mathrm{C}$ had higher mean VAS score throughout the study period. No side effects were found among the groups. These two results were clinically and statistically significant $(p<0.05)$.

\section{CONCLUSIONS}

Administration of intra-articular inj. ropivacaine $0.25 \%, 20 \mathrm{ml}$, is effective \& safe method of management of postoperative pain in patients undergoing arthroscopic knee surgeries, as it prolongs the duration of postoperative analgesia, provides better quality of analgesia with reduced requirement of rescue analgesia without significant side effects.

\section{KEY WORDS}

Intra-Articular, Ropivacaine, Post-Operative Analgesia, Arthroscopic, Knee Surgeries

\author{
Corresponding Author: \\ Dr. Anjali Modak, \\ 204, Fortune Empire, SBI Building, \\ Opp. Tajshree Honda Showroom, \\ Manish Nagar, Nagpur-440034, \\ Maharashtra, India. \\ E-mail: anjaliborkar93@gmail.com
}

DOI: $10.14260 / \mathrm{jemds} / 2020 / 74$

Financial or Other Competing Interests: None.

How to Cite This Article:

Nagpure P, Modak A, Singam A, et al. Effectiveness of intra-articular ropivacaine for post-operative analgesia in arthroscopic knee surgeries. J. Evolution Med. Dent. Sci. 2020;9(06):324-328, DOI: 10.14260/jemds/2020/74

Submission 25-11-2019,

Peer Review 17-01-2020,

Acceptance 22-01-2020,

Published 10-02-2020.

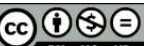




\section{BACKGROUND}

Pain is a complex, unpleasant, emotional and sensory feeling associated with injury to the tissues. WHO recognises pain as a fifth vital sign along with pulse, blood pressure, temperature and respiration. Post-operative pain is major hindrance to recovery hence it necessitates effective postoperative analgesia by more suitable methods and drugs. ${ }^{1}$ Arthroscopic knee surgery is one of the most common minimally invasive surgical procedure in modern orthopaedic setup. It is associated with variable amount of postoperative pain, which is caused by irritation of free nerve endings of synovial tissue, anterior fat pad, and joint capsule during surgical excision and resection. ${ }^{2}$ undoubtedly, postoperative pain has a negative impact on patient's early mobilization, rehabilitation, and psychology, leading to prolonged hospital stay.

Any method of post-operative analgesia must meet 3 basic criteria: effectivity, safety, feasibility. Administration of oral opioids and non-steroid anti-inflammatory drugs can provide sufficient relief of pain in the immediate postoperative period. Several analgesic strategies such as systemic medication, central or peripheral nerve block, have been used to interrupt the pain pathway. ${ }^{3}$ However, none is free from limitations such as need for special equipment like, patient controlled analgesia pumps, monitoring in cases of systemically administered opioids, skill for epidural catheter placement and risk of complications like nausea, gastritis in cases of systemically administered NSAIDS. Utilizing the peripheral receptors for postoperative pain management is an important mode of analgesia. The intra-articular route of drug administration is an example for management of pain after joint surgery utilizing the peripheral receptors. It provides analgesia locally with minimal systemic side effects. ${ }^{3}$

Spinal anaesthesia is often preferred for arthroscopic knee surgery, because of the procedure's low level of difficulty, reduced incidence of nausea or vomiting, but the duration of postoperative analgesia is not prolonged by spinal anaesthesia when given only with local anaesthetic like bupivacaine. ${ }^{4}$ During spinal anaesthesia, the addition of intrathecal opioids like fentanyl allows the use of less local anaesthetic, provides analgesia in the postoperative period, but may cause sideeffects like urinary retention, pruritus, nausea and vomiting. ${ }^{2}$ Thus, intra-articular drug administration at the end of surgery can be used as a strategy for management of postoperative pain after arthroscopic knee surgeries performed under spinal anaesthesia. ${ }^{3}$ Local anaesthetics block transmission of action potentials through inhibition of related sodium channels. Bupivacaine a long-acting local anaesthetic, is associated with cardiotoxicity when used in high concentration or after accidental intravascular administration. Also, there are studies where in both bupivacaine $0.5 \%$ and bupivacaine $0.25 \%$ demonstrated dose-dependent chondrotoxicity. 5,6

Ropivacaine a relatively newer long-acting local anaesthetic, structurally related to bupivacaine. Ropivacaine is a pure $\mathrm{S}(-)$ enantiomer, which is a racemate, developed for decreasing the potential toxicity and improving relative sensory and motor block profiles. ${ }^{7}$ Ropivacaine causes reversible inhibition of sodium ion influx, and thereby blocks impulse conduction in nerve fibres, along with dosedependent inhibition of potassium channels. Ropivacaine being less lipophilic in comparison to bupivacaine, it selectively acts on the pain-transmitting $\mathrm{A} \delta$ and $\mathrm{C}$ nerves rather than $A \beta$ fibres, which are involved in motor function. ${ }^{5}$ Thus ropivacaine provides more effective analgesia $\&$ can be used for pain management after arthroscopic knee surgeries when given intra-articularly. Various studies have used inj. ropivacaine intra-articularly in concentrations of $0.75 \%, 0.5 \%$, $0.25 \%$ \& volumes of $30 \mathrm{ml}, 20 \mathrm{ml}, 10 \mathrm{ml}$, after knee arthroscopy for postoperative analgesia and were found effective to prolong the duration of postoperative analgesia after arthroscopic knee surgery.2,8,9,10,11,12

Therefore this study was planned to evaluate the efficacy and safety of intraarticularly injected ropivacaine $0.25 \%$, $20 \mathrm{ml}$, after knee arthroscopy performed under spinal anaesthesia, for prolonging the duration of post-operative analgesia.

\section{METHODS}

This is a prospective, randomized study done for evaluating the effect of intra-articularly administered inj. ropivacaine $0.25 \% 20 \mathrm{ml}$, after arthroscopic knee surgery for prolonging the duration postoperative analgesia. After obtaining prior permission from the institutional ethical committee \& written informed consent from all patients, this study was conducted in the Department of Anaesthesiology, Acharya Vinoba Bhave Rural Hospital, affiliated to Jawaharlal Nehru Medical College, Sawangi Meghe between August 2017 to September 2019 on 80 patients posted for elective arthroscopic knee surgeries like meniscectomy, chondral debridement, loose body removal \& diagnostic arthroscopy, under spinal anaesthesia.

ASA class I and II patients, aged 18 to 60 years, willing to participate, weighing between $40-80 \mathrm{kgs}$ undergoing arthroscopic knee surgeries within a time duration of 60-120 mins, were included in the study. Patients with malignant disease, bleeding disorders, cardiac disease, liver or kidney dysfunction, received any analgesics within $24 \mathrm{hr}$ period prior to the study, known cases of allergic reactions to local anaesthetic were excluded from the study.

One day prior to surgery pre-anaesthetic check-up was done of all the patients. After taking a detailed history, thorough general \& systemic examination was done to rule out any cardiovascular, respiratory or neurological problem. Weight and routine investigations were recorded. Written informed consent was taken from all the patients before surgery. Patients were explained regarding spinal anaesthesia, the operative procedure \& the Visual Analog Scale (VAS) during the pre-anaesthetic visit. As per the scale, 0 on the scale was considered as no pain \& 10 was considered as the worst imaginable pain..$^{13}$ All the patients were divided randomly into two groups of 40 each, by computer generated random number table and allocation of the same by sealed envelope technique.

Group R- Patients who were given $20 \mathrm{ml}$ of $0.25 \%$ inj. ropivacaine intra-articularly,

Group C- Patients who were given $20 \mathrm{ml}$ of $0.9 \%$ inj. normal saline intra-articularly.

On the arrival of the patient in the operating room, an 18gauge/20-gauge intravenous cannula was secured and an infusion of ringer lactate was started at the rate of $10 \mathrm{ml} / \mathrm{kg}$ initially to correct the deficit followed by maintenance of $2 \mathrm{ml} / \mathrm{kg}$. A multipara monitor was connected to the patient and 
vitals such as pulse rate (PR), mean arterial pressure (MAP), systolic blood pressure (SBP), diastolic blood pressure (DBP), percentage saturation of oxygen (SpO2), respiratory rate \& ECG were recorded as baseline reading. Subarachnoid block was given under all aseptic precautions in sitting position, with inj. bupivacaine $0.5 \%$ (Heavy) $3 \mathrm{ml}$, by a 25-gauge Quincke's spinal needle at the L3-L4 interspace. Immediately supine position was given to patient.

Sensory \& motor level was achieved between T8 to T10 after checking with pin prick method and then tourniquet was applied on the lower limb to be operated with 250-350 mm Hg of inflation pressure, continuously in the course of surgery. At the completion of the surgery, the study drug was prepared by a different anaesthesiologist who was not a part of postoperative monitoring. The study drug was prepared in a sterile bowl \& was given to surgeon for intra-articular administration in all the patients according to the group they belonged to, in an aseptic manner \& this was considered as 0 $\mathrm{hr}$. Tourniquet was released, 10 minutes after intra-articular drug injection. In postoperative period to avoid bias in the study, anaesthesiologist who was not a part of drug preparation, monitored the patient. Pain was assessed using visual analog scale \& hemodynamic parameters like pulse rate, mean arterial blood pressure, respiratory rate, percentage saturation of oxygen were recorded at $0,1^{\text {st }}, 2^{\text {nd }}, 4^{\text {th }}, 6^{\text {th }}, 8^{\text {th }}, 12^{\text {th }}, 16^{\text {th }}, 20^{\text {th }} \& 24^{\text {th }}$ hours which was considered to be the end point of the study. In intraoperative period if any patient complained of pain \& required any rescue analgesic, that patient was excluded from our study.

Postoperatively at VAS score $\geq 4$, the time recorded \& inj. paracetamol 1gm I.V. was administered as rescue analgesia. The parameters recorded \& compared between both the groups were, duration of postoperative analgesia (The time from the intra-articular injection of study drug to the requirement of first rescue analgesia), Quality of analgesia by assessment of VAS score at different time intervals till 24 hours post-operatively, Total number of rescue analgesic doses given till 24 hours post-operatively and side effects like change in vital parameters, convulsions, arrythmias, etc. All the data was entered in the excel sheet. The quantitative data were expressed as mean \pm standard deviation and all qualitative data was expressed as percentage. Quantitative data was analyzed by using student $t$ test \& qualitative data was analyzed by using Chi-square test. Data was analysed by SPSS 20.0 version \& Graph Pad Prism 6.0 version \& $p<0.05$ was considered statistically significant.

\section{Sample Size}

Assuming mean total number of rescue analgesic requirement in first 24 hours post-operatively 1.75 and standard deviation of 0.72 (with reference to study done by Hazra et al ${ }^{14}$ ) keeping power at $80 \%$, and confidence interval of $95 \%$ (alpha error at 0.05 ), a sample size of 35 patients would be required to detect a minimum of $25 \%(0.43)$ difference in the mean total number of rescue analgesic in the two groups. We included 40 patients in each group to compensate for possible dropouts. Sample size was calculated through https://www.openepi.com.

\section{RESULTS}

In this study, patients were comparable amongst the two groups with respect to age, weight, gender, ASA class \& duration of surgery as shown in Table $1 .(p>0.05)$. In this study, no statistically significant difference was observed amongst the two groups in terms of type of surgery as shown in table 2. The difference amongst the two groups was nonsignificant with respect to hemodynamic parameters like, mean pulse rate, mean arterial pressure \& mean oxygen saturation at different time intervals till 24hours postoperatively $(p>0.05)$. Mean duration of postoperative analgesia was compared between 2 groups \& it was noted that this time was significantly more in patients of Group $\mathrm{R}$ $(255.15 \pm 26.35 \mathrm{mins})$ than in patients of Group C $(92.40 \pm 12.54$ mins).

\begin{tabular}{|c|c|c|}
\hline & Group R & Group C \\
\hline Age in yrs. & $32.0 \pm 9.3$ & $32.0 \pm 9$ \\
\hline Weight in kgs. & $62.175 \pm 6.14$ & $62.65 \pm 6.61$ \\
\hline ASA class (I/II) & $21 / 19$ & $26 / 14$ \\
\hline Gender (M/F) & $30 / 10$ & $29 / 11$ \\
\hline Duration of surgery & $114.74 \pm 5.74$ & $115.05 \pm 5.65$ \\
\hline \multicolumn{2}{|c|}{ Table 1. Demographic Data, ASA Class \& } \\
Duration of Surgery of Patients \\
\hline
\end{tabular}

\begin{tabular}{|c|c|c|c|}
\hline Type of Surgery & Group R & Group C & \multirow{2}{*}{ p value } \\
\hline Meniscectomy & $27(67.5 \%)$ & $25(62.5 \%)$ & \\
\hline Chondral debridement & $6(15 \%)$ & $6(15 \%)$ & \multirow{2}{*}{$\mathrm{p}=0.64, \mathbf{N S}$} \\
\hline Loose body removal & $5(12.5 \%)$ & $6(15 \%)$ & \\
\cline { 1 - 3 } Diagnostic arthroscopy \& lavage & $2(5 \%)$ & $3(7.5 \%)$ & \\
\cline { 1 - 2 } Total & $\mathbf{4 0 ( 1 0 0 \% )}$ & $\mathbf{4 0 ~ ( 1 0 0 \% )}$ & \\
\cline { 1 - 2 } Table 2. Distribution of Patients According to Type of Surgery \\
\hline (NS-Non-Significant)
\end{tabular}

\begin{tabular}{|c|c|c|c|}
\hline $\begin{array}{c}\text { Mean duration of Postoperative } \\
\text { Analgesia (min) }\end{array}$ & Group R & Group C & p-value \\
\hline $0-120$ & 0 & $39(97.5 \%)$ & \multirow{4}{*}{$\mathrm{p}<0.01, \mathrm{~S}$} \\
\hline $121-240$ & $12(30 \%)$ & $1(2.5 \%)$ & \\
\hline $241-300$ & $28(70 \%)$ & 0 & \\
\hline Time \pm SD (minutes) & $255.15 \pm 26.35$ & $92.40 \pm 12.54$ & \\
\hline \multicolumn{4}{|c|}{$\begin{array}{c}\text { Table 3. Distribution of Patients According to } \\
\text { Duration of Postoperative Analgesia }\end{array}$} \\
\hline
\end{tabular}

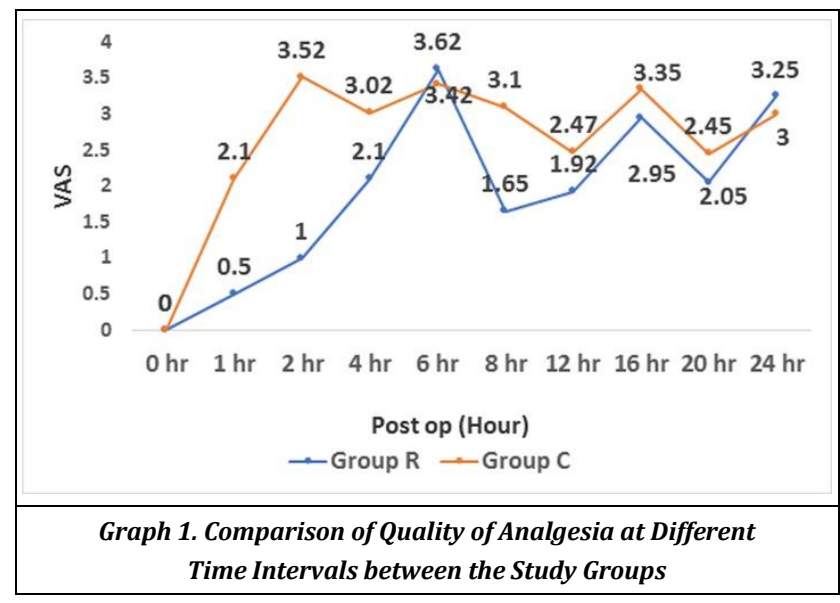

The comparison of mean VAS score at different time intervals in between the study groups was done as shown in Graph 1 . The patients in both groups were comparable on the basis of $0 \mathrm{hr}$., mean VAS score, as mean VAS score was 0 in both 
the groups. Among the patients of group R, the mean VAS during the $1^{\text {st }} \& 2^{\text {nd }}$ hours was $0.5 \pm 0.5 \& 1 \pm 0.76$ respectively, whereas among the subjects of group $\mathrm{C}$, the mean VAS during the $1^{\text {st }} \& 2$ nd hour was $2.1 \pm 0.44 \& 3.52 \pm 0.90(p<0.01)$. Mean VAS among the subjects of group $\mathrm{R}$ was significantly lower in comparison to Group C at $1^{\text {st }} \mathrm{hr}$., $2^{\text {nd }} \mathrm{hr}$., $4^{\text {th }} \mathrm{hr}$., $8^{\text {th }} \mathrm{hr}$., $12^{\text {th }} \mathrm{hr}$., $16^{\text {th }} \mathrm{hr} . \& 20^{\text {th }} \mathrm{hr}$. postoperatively $(\mathrm{p}<0.05)$. The total number of rescue analgesic doses required till $24 \mathrm{hrs}$. postoperatively were significantly less in patients of Group R $(1.32 \pm 0.52)$ than in patients of Group C $(3.0 \pm 1.0)$. (Table 4$)$

\begin{tabular}{|c|c|c|c|}
\hline $\begin{array}{c}\text { Number of Doses of } \\
\text { Rescue Analgesia }\end{array}$ & Group R & Group C & p Value \\
\hline 1 & $28(70 \%)$ & $2(5 \%)$ & \multirow{2}{*}{$\mathrm{p}=0.01, \mathrm{~S}$} \\
\hline 2 & $11(27.5 \%)$ & $6(15 \%)$ & $32(80 \%)$ \\
\hline 3 & $1(2.5 \%)$ & $3.0 \pm 1.0$ & \\
\hline Mean \pm SD & $1.32 \pm 0.52$ & Table 4. Distribution of Patients According to the \\
Number of Doses of Rescue Analgesia Required \\
\hline \multicolumn{3}{|c|}{} \\
\hline
\end{tabular}

\section{DISCUSSION}

Arthroscopic knee surgery is done as a daycare procedure using a variety of anesthetic techniques. This procedure involves repair of menisci and ligaments through a small incision, and additional analgesia is required to provide pain relief due to substantial pain complained by the patients postoperatively as anaesthetic effect wears off. 15,16 Several techniques are available to alleviate pain following arthroscopic surgery. The advantage can be in terms of better pain relief or decreased consumption of supplemental analgesics and allowing early mobilization and rehabilitation of the patient. One of such method used is Intra-articular local anesthetics administration at the end of arthroscopic procedure.

Ropivacaine is a local anaesthetic agent which is longacting, it has a high $\mathrm{pKa}$ and low-lipid solubility. It has enhanced cardiovascular and CNS safety in comparison to bupivacaine. Ropivacaine produces less motor block as compared to bupivacaine even after having similar onset, quality \& duration of sensory block as that of bupivacaine. Many animal \& human experiments have confirmed the lesser toxicity of Ropivacaine in comparison to Bupivacaine. ${ }^{17}$ In our study we have used inj. ropivacaine $0.25 \%$ for intra-articular administration for postoperative analgesia. Kaushik and his associates did a study in 2018, they administered ropivacaine $0.2 \%$ intraarticularly \& observed that it reduced pain in the first few hours of post-operative period after knee arthroscopy. ${ }^{18}$

In this study, patients were comparable amongst the two groups with respect to age, weight, gender, ASA class, duration of surgery \& type of surgery. (table 1,2).

The difference amongst the two groups was non-significant with respect to hemodynamic parameters like, mean pulse rate, mean arterial pressure \& mean oxygen saturation at different time intervals till 24 hours postoperatively. Similar results were found in the studies by Panigraphi et al \& Senapati et al. ${ }^{19,9}$ Duration of postoperative analgesia was compared between 2 groups \& it was noted that this time was significantly more in patients of Group $\mathrm{R}(255.15 \pm 26.35$ mins.) than in patients of Group C ( $92.40 \pm 12.54$ mins.)..This difference can be attributed to the action of ropivacaine that causes reversible inhibition of sodium ion influx, and thereby blocks impulse conduction in nerve fibres, along with dose-dependent inhibition of potassium channels. ${ }^{14}$ Similar results were obtained by Kaushik et al in their study, wherein the mean time for the requirement of first post-operative rescue analgesia after the use of intra-articular ropivacaine was $262.43 \pm 57$ minutes. ${ }^{18}$

Graph 1 shows the comparison of mean VAS score in between the study groups at various time intervals till $24 \mathrm{hrs}$. postoperatively. In comparison to the baseline ( $0 \mathrm{hr}$.) values which was similar in both the groups the mean VAS among the subjects of group $\mathrm{R}$ was significantly lower in comparison to Group C at $1^{\text {st }} \mathrm{hr}$., $2^{\text {nd }} \mathrm{hr} ., 4^{\text {th }} \mathrm{hr} ., 8^{\text {th }} \mathrm{hr} ., 12^{\text {th }} \mathrm{hr} ., 16^{\text {th }} \mathrm{hr} . \& 20^{\text {th }}$ hr., postoperatively. Except 6 th and 24 th post-operative hours, ropivacaine group patients showed significantly less VAS scores up to 24 hours post-operatively except $6^{\text {th }} \& 24^{\text {th }}$ hour postoperatively. The higher mean VAS score at 6th postoperative hours in Group $\mathrm{R}$ was probably due to administration of rescue analgesics in group $\mathrm{C}$ before the time of scheduled observation. At 24th postoperative hour, there was no significant difference in VAS scores between both the groups ( $p>0.05)$. So, it was clearly found that analgesic efficacy of intra-articular ropivacaine $0.25 \%$ was better at least up to first 12 hours postoperatively. Similar results were obtained by Franceschi et al in 2001, i.e. VAS scores after intraarticular ropivacaine use was 0.33 at postoperative hour 1 , and 0.87 at postoperative hour $4 .^{20}$ These findings were also supported by Hazra et al in 2015, as in their study except 6th post-operative hours, use of intra-articular ropivacaine showed significantly less VAS scores up to 12 hours post-operatively $(p<0.05) .14$ Thus it can be said that the quality of analgesia of intraarticular ropivacaine is better.

The total number of rescue analgesic doses required till 24 hrs. postoperatively were significantly less in patients of Group R (1.32 \pm 0.52$)$ than in patients of Group C (3.0 \pm 1.0$)$. (table 4).Similar results were observed in a study conducted by Manuar et al in 2014, wherein total rescue analgesia requirement was $1.394 \pm 0.496$ after the use of intra-articular ropivacaine. ${ }^{3}$ The patients requiring 3 doses of rescue analgesics at different time intervals till 24 hours of postoperative period was significantly lower in Group R, that is suggestive of better quality of analgesia. In our study none of the patients developed any adverse reactions therefore we assume that intraarticular dose of ropivacaine $0.25 \% 20 \mathrm{ml}$ is safe. Similar results were observed in a study conducted by Panigrahi et al where in no adverse effects were reported during the first $24 \mathrm{~h}$ after surgery. ${ }^{19}$

\section{CONCLUSIONS}

Administration of intra-articular inj. ropivacaine $0.25 \%, 20 \mathrm{ml}$, is effective \& safe method of management of postoperative pain in patients undergoing arthroscopic knee surgeries, as it prolongs the duration of postoperative analgesia, provides better quality of analgesia with reduced requirement of rescue analgesia without significant side effects.

\section{Limitations}

We did not compare ropivacaine with its other routes of administration like epidural, also plasma levels of locally 
administered ropivacaine for toxicity were not checked and long-term follow-up of the patients regarding any local tissue damage (chondrolysis) occurred in intra-articular space due to ropivacaine was not noted.

\section{REFERENCES}

[1] Miller RD, Eriksson LI, Fleisher LA, et al. Intra-articular analgesia. Miller's Anesthesia. $8^{\text {th }}$ edn. London: Churchill Livingstone/ Elsevier 2015;61:769-83.

[2] Gürkan Y, Canatay H, Özdamar D, et al. Spinal anesthesia for arthroscopic knee surgery. Acta Anaesthesiologica Scandinavica 2004;48(4):513-7.

[3] Manuar MB, Majumdar S, Das A, et al. Pain relief after arthroscopic knee surgery: a comparison of intraarticular ropivacaine, fentanyl and dexmedetomidine: a prospective, double-blinded, randomized controlled study. Saudi Journal of Anaesthesia 2014;8(2):233-7.

[4] Sagir O, Ozaslan S, Erduran M, et al. Comparison between intrathecal hyperbaric bupivacaine and levobupivacaine for ambulatory knee arthroscopy. World Journal of Anesthesiology 2013;2(3):18-25.

[5] Nahravani M, Tekye SMM, Alipour M, et al. Analgesia following arthroscopy-a comparison of intra-articular bupivacaine and/or midazolam and or fentanyl. Archives of Bone and Joint Surgery 2017;5(1):28-31.

[6] Webb ST, Ghosh S. Intra-articular bupivacaine: potentially chondrotoxic? British J Anaesthesia 2009;102(4):439-41.

[7] Kuthiala G, Chaudhary G. Ropivacaine: a review of its pharmacology and clinical use. Indian Journal of Anaesthesia 2011;55(2):104-10.

[8] Das A, Majumdar S, Kundu R, et al. Pain relief in day care arthroscopic knee surgery: a comparison between intraarticular ropivacaine and levobupivacaine: a prospective, double-blinded, randomized controlled study. Saudi Journal of Anaesthesia 2014;8(3):368-73.

[9] Senapati S, Basu A, Bhattacharya D, et al. Comparison of analgesic effect of intra-articular administration of levobupivacaine and clonidine versus ropivacaine and clonidine in day care knee arthroscopic surgery under spinal anesthesia. Indian Journal of Pain 2016;30(1):3842.

[10] Rokhtabnak F, Ale Bouyeh MR, Siamdust AS, et al. Comparison of the effects of intra-articular sole ropivacaine and combined ketorolac and ropivacaine for pain control after knee arthroscopy surgery. British Journal of Pain 2015;9(3):149-56.
[11] Ng HP, Nordström U, Axelsson K, et al. Efficacy of intraarticular bupivacaine, ropivacaine or a combination of ropivacaine, morphine, and ketorolac on postoperative pain relief after ambulatory arthroscopic knee surgery: a randomized double-blind study. Regional Anesthesia \& Pain Medicine 2006;31(1):26-33.

[12] Marret E, Gentili M, Bonnet MP, et al. Intra-articular ropivacaine $0.75 \%$ and bupivacaine $0.50 \%$ for analgesia after arthroscopic knee surgery: a randomized prospective study. Arthroscopy: The Journal of Arthroscopic \& Related Surgery 2005;21(3):313-6.

[13] Aitkenhead RA, Rowbotham JD, Smith G. Physiology and measurement of pain. Text book of anaesthesia. $4^{\text {th }}$ edn. London: Churchill Livingstone 2001: p. 201-10.

[14] Hazra R, Manuar MB, Manjunatha SM, et al. Analgesic effects of intra-articular ropivacaine following arthroscopic knee surgery: results of a double-blind, randomized controlled trial between two different doses. Asian Journal of Medical Sciences 2015;6(1):81-6.

[15] Barash GP, Cullen FB, Stoelting KR, et al. Clinical anesthesia. In: Terese TH, Denise JW, eds. Anaesthesia for Orthopaedic Surgery. $6^{\text {th }}$ edn. India: Wolters \& Kluwer 2009: p. 1385.

[16] Miller RD, Eriksson IL, Fleisher AL, et al. Miller's Anesthesia. In: Michael KU, edr. Anesthesia for Orthopedic Surgery. $7^{\text {th }}$ edn. Philadelphia: Churchill Livingstone 2010: p. 2249-50.

[17] Hansen TG. Ropivacaine: a pharmacological review. Expert Review of Neurotherapeutics 2004;4(5):781-91.

[18] Kaushik PHS, Kamath SS, Kaminuath SU. A comparison between intra-articular $0.2 \%$ ropivacaine and $0.25 \%$ bupivacaine for post-operative analgesia following daycare arthroscopic knee surgeries. Asian Journal of Pharmaceutical and Clinical Research 2018;11(2):422-6.

[19] Panigrahi R, Roy R, Mahapatra AK, et al. Intra-articular adjuvant analgesics following knee arthroscopy: comparison between single and double dose dexmedetomidine and ropivacaine a multicenter prospective double-blind trial. Orthopaedic Surgery 2015;7(3):250-5.

[20] Franceschi F, Rizzello G, Cataldo R, et al. Comparison of morphine and ropivacaine following knee arthroscopy. Arthroscopy: The Journal of Arthroscopic \& Related Surgery 2001;17(5):477-80. 